\section{PC-045 IMPACT OF THE PREPARATION OF A CLINICAL SOLUTION OF RITUXIMAB 1.0 MG/ML ON THE PARTICULATES (AGGREGATION) MEASURED BY DYNAMIC LIGHT SCATTERING: SODIUM CHLORIDE AND GLUCOSE CONCENTRATION, AND AGITATION EFFECT}

${ }^{1} \mathrm{~N}$ Natalia-Iglesias*, 'J Hermosilla, ${ }^{1 \mathrm{~J}}$ Exposito, ${ }^{2} \mathrm{~A}$ Salmerón-Garcia, ${ }^{2} \mathrm{~J}$ Cabeza. ${ }^{1}$ Science Faculty-Institute for Biomedical Research-University of Granada, Analytical Chemistry, Granada, Spain; ${ }^{2}$ San Cecilio University Hospital/Institute for Biomedical Research, Clinical Pharmacy, Granada, Spain

\subsection{6/ejhpharm-2020-eahpconf.92}

Background and importance Rituximab (RTX) is a therapeutic monoclonal antibody used for the treatment of certain types of cancer. As a complex protein, routine handling or unintentional mishandling of its solutions may cause degradation that could remain unnoticed but could potentially compromise the clinical safety and efficacy of the drug product. ${ }^{1}$

Aim and objectives To assess the impact on the RTX (Mabthera) aggregation process promoted by slight modification in the concentration of the compound $(\mathrm{NaCl} 0.9 \%$ and glucose $5 \%$ ) used to prepare the clinical diluted solution of RTX 1.0 $\mathrm{mg} / \mathrm{mL}$. Also, to assess the impact on the aggregation of RTX clinical diluted solutions $(1.0 \mathrm{mg} / \mathrm{mL}$ in $\mathrm{NaCl} 0.9 \%$ and glucose $5 \%$ ) promoted by manual shaking.

Material and methods RTX (Mabthera $10 \mathrm{mg} / \mathrm{mL}$ ) was diluted to $1 \mathrm{mg} / \mathrm{mL}$ using different $\mathrm{NaCl}$ (from $0.5 \%$ to $1.5 \%$ ) and glucose (from $1 \%$ to $10 \%$ ) concentrations. Manual gentle shaking was performed for 10 minutes. Particulate was tracked by dynamic light scattering (DLS) and readings were carried out in a protein solution DynaPro-99 system dynamic light scattering module equipped with a temperature control micro sampler (Wyatt, Santa Barbara, California, USA) for obtaining the hydrodynamic radius (HR) and polydispersity.

Results Reference $1.0 \mathrm{mg} / \mathrm{mL}$ RTX samples diluted in $\mathrm{NaCl}$ $0.9 \%$ and glucose $5 \%$ showed a single particulate population with a HR of $10.51 \pm 2.210 \mathrm{~nm}$ and $10.72 \pm 2.694 \mathrm{~nm}$, respectively, attributed to monomers of RTX. No significant changes were obtained for HR when the concentration of the diluents was changed. Also, no significant changes were observed when the samples were shaken, with the HR values always within the interval of the size of the monomers. Polydispersity remained unchanged in all of the samples analysed.

Conclusion and relevance Variation in $\mathrm{NaCl}$ and glucose concentrations around clinical concentrations of $0.9 \%$ and $5 \%$ did not promote aggregation in a $1 \mathrm{mg} / \mathrm{mL}$ RTX solution detected by DLS. Also, shaking did not have any impact on aggregation in this clinical RTX solution.

\section{REFERENCES AND/OR ACKNOWLEDGEMENTS}

1. Nejadnik MR, et al. J Pharm Sci 2018;107:2013-2019.

Funded by Project FIS: PI-17/00547 (Instituto Carlos III, Spain), which means that it was also partially supported by the European Regional Development Funds.

No conflict of interest.

\section{PC-046 PARENTERAL NUTRITION ADMIXTURES: REVIEW OF THE MICROBIOLOGICAL SAMPLING PLAN}

${ }^{1} \mathrm{C}$ Sampaio*, ${ }^{1} \mathrm{~A}$ Capela, ${ }^{1} \mathrm{R}$ Barbosa, ${ }^{1} \mathrm{~S}$ Fraga, ${ }^{1} \mathrm{~T}$ Soares, ${ }^{2} \mathrm{M}$ Ribeiro, ${ }^{2} \mathrm{C}$ Teixeira. ${ }^{1} \mathrm{Centro}$ Hospitalar Universitário São João, Pharmacy, 4200-319 Porto, Portugal; ${ }^{2}$ Centro Hospitalar Universitário São João, Clinical Pathology, 4200-319 Porto, Portugal

\subsection{6/ejhpharm-2020-eahpconf.93}

Background and importance Sterility testing of parenteral nutrition $(\mathrm{PN})$ is described in pharmacopoeias and establishes the minimum number of units that must be tested. Normally, no quality control testing is performed for extemporaneously prepared products. In our procedure, to evaluate the efficacy of the working method, samples are taken from personalised and stock PN mixtures as part of the control process.

Aim and objectives To evaluate the number of PN samples taken for microbiological control and its compliance with pharmacopoeial specifications. To test the possibility of reducing the number of PN samples taken and the economic impact associated with this.

Material and methods This was a retrospective study of the microbiological control of PN bags from October 2018 to September 2019. Data were obtained from pharmacy and microbiology laboratory records. The parameters measured were: PN bags produced, PN samples taken versus recommended by pharmacopoeial specifications and economic impact. Costs were calculated considering the value attributed to the sterility test.

Results During the studied period, 12466 PN bags were prepared and 1723 were tested. Four of the control bags had a positive result $(0.23 \%)$. In no case was the result compatible with infection or isolation of the same microorganism in blood culture. Analysis of the data by day of the week showed an average number of bags assessed for control/prepared of 7/49 (Monday), 4/26 (Tuesday), 7/42 (Wednesday), 7/51 (Thursday) and 9/76 (Friday). According to the pharmacopoeial specifications, for production less than 100 units, the minimum number of units to be tested should be $10 \%$ or 4 units, whichever is greater. Therefore, applying these average values to the production, the minimum number of samples taken should be: 5 (Monday), 4 (Tuesday), 4 (Wednesday), 5 (Thursday) and 8 (Friday). The predictable decrease in the number analysed would imply a cost saving of $€ 9575 /$ year.

Conclusion and relevance The procedure in operation consists of random sampling of 1 in 5 prepared PN bags. These results, as well as a history of low and stable positive controls, will allow an increase in the sampling interval to 1 in 10. The cost saving achieved will allow other studies to be performed with the microbiology team, improving the management of material and human resources.

\section{REFERENCES AND/OR ACKNOWLEDGEMENTS}

No conflict of interest. 